\title{
Action Regulation at the Work-Family Interface: Nomological Network and Work-Family Consequences
}

\author{
Andreas Hirschi ${ }^{1}$ (I) Nicola von Allmen ${ }^{1} \cdot$ Anne Burmeister $^{2} \cdot$ Hannes Zacher $^{3}$
}

Accepted: 5 May 2021 / Published online: 19 May 2021

(c) The Author(s) 2021

\begin{abstract}
Pursuing personally valued goals in work and family is important for many people, yet research has only partially addressed how individuals can actively manage the work-family interface. We examined the role of action regulation at the work-family interface (AR-WF) as an integrated individual-level approach to attain favorable work-family outcomes through the selection and pursuit of goals at the work-family interface. We investigated the relation of AR-WF to theoretically derived correlates and outcomes in two time-lagged studies with samples from the USA and Germany, based on a newly developed and validated measure to assess AR-WF. Overall, results showed that AR-WF is positively related to dispositional self-regulation, work and family role commitment, work and family goal regulation, and work and family social support. In contrast, AR-WF was largely unrelated to work and family role demands and segmentation or integration boundary enactment. AR-WF further positively related to work and family goal attainment, as well as work-family enrichment beyond related constructs. However, AR-WF was also positively related to increased work-to-family conflict. We discuss how a focus on action regulation can be useful for attaining a better understanding of the active role that people play in managing multiple role demands at the work-family interface.
\end{abstract}

Keywords Work-family interface $\cdot$ Action regulation $\cdot$ Boundary management $\cdot$ Multiple roles

Technological changes, shifting gender norms, and an increase of women in the workforce have led to a close intersection of work and family domains for many people (Greenhaus \& Kossek, 2014). As a consequence, the work-family interface in terms of experienced conflict and enrichment between these life domains is meaningfully related to important personal and organizational outcomes, such as job satisfaction, turnover intentions, or well-being (Shockley, 2018). It is hence important to understand how individuals can successfully manage work and family roles.

Work-family research has predominantly focused on role demands, contextual or personal resources, or personality

Andreas Hirschi

andreas.hirschi@psy.unibe.ch

1 Institute for Psychology, University of Bern, Fabrikstrasse 8, CH-3012 Bern, Switzerland

2 Rotterdam School of Management, Erasmus University, Burgemeester Oudlaan 50, Mandeville (T) Building, 3062 PA Rotterdam, The Netherlands

3 Institute of Psychology, Leipzig University, Neumarkt 9-19, 04109 Leipzig, Germany traits as predictors of work-family conflict and enrichment (e.g., Allen et al., 2012; Byron, 2005; Lapierre et al., 2018). Work-family conflict ${ }^{1}$ represents a form of inter-role conflict in that work and family roles are mutually incompatible in some regard (Greenhaus \& Beutell, 1985). Work-family enrichment occurs if experiences in one role improve performance and enhance positive affect in the other role (Greenhaus \& Powell, 2006). However, the active role that individuals play in managing their work and family roles has received comparably little empirical attention in work-family research (Edwards \& Rothbard, 2000; Hirschi et al., 2019). This is surprising, given that several theoretical models stress that action regulation, boundary management strategies, role management, and intentional resource allocation across roles are important for successfully integrating work and family roles (Grawitch et al., 2010; Hirschi et al., 2019; Marks \& MacDermid, 1996; Voydanoff, 2005). Existing empirical research along these lines mostly focused on boundary management in terms of whether people prefer

\footnotetext{
${ }^{1}$ For simplicity, we use the term work-family to include both directions of conflict and enrichment (i.e., work-to-family and family-towork) and speak of work-to-family and family-to-work when we refer to the specific direction of effects.
} 
or enact stronger or weaker boundaries across life roles (Allen et al., 2014; Shockley et al., 2017). However, boundary management is only one specific strategy of how people can actively shape the work-family interface. Importantly, boundary preferences and enactment do not directly address self-regulatory processes that determine how people set and pursue goals in different life roles, adapt to changing role demands, or allocate resources across life roles (Grawitch et al., 2010; Hirschi et al., 2019; Marks \& MacDermid, 1996; Voydanoff, 2005). This is an important omission because it limits the understanding of how people can actively manage different life roles in a way that leads to favorable role outcomes. It also poses important limitations on practice applications that could help individuals achieve a better work-nonwork interface through increased personal agency.

One likely reason for this state of affairs is that many existing theoretical models do not explicate the self-regulatory mechanisms that constitute the active management of work and nonwork roles. In addition, apart from scales that tap into boundary preferences and enactment (e.g., Kossek et al., 2012; Wepfer et al., 2018), there is a lack of validated measures that assess self-regulatory processes in role management behaviors. This poses a constraint on future empirical research aiming to better understand the theoretical predictors, correlates, and outcomes of actively managing work and family roles.

To address these issues, we draw on action regulation theory (ART; Frese \& Zapf, 1994; Zacher \& Frese, 2018) to introduce the concept of action regulation at the work-family interface (AR-WF), defined as active, goal-directed behaviors to pursue goals across work and family domains. We specifically propose that people actively manage work and family roles by engaging in goal selection and development across work and family roles, mapping resources and barriers related to goal attainment, planning how to achieve goals in both life domains, and monitoring and processing feedback on goal progress (Hirschi et al., 2019). Based on this perspective, our paper aims to theoretically develop and empirically test the nomological net of AR-WF, including its relation to prominent work-family outcomes, using two time-lagged studies conducted in the USA and Germany with a newly developed and validated AR-WF measure. As such, our studies contribute to the work-family literature in several ways: First, we advance the theoretical perspective that favorable outcomes at the work-family interface (i.e., goal attainment, reduced conflict, enhanced enrichment) can be achieved by engaging in a set of action regulation behaviors across work and family roles. Second, we clarify the nomological net of AR-WF in relation to a series of self-regulation (e.g., dispositional self-regulation) and work-family constructs (e.g., boundary enactment). Third, we offer a new set of validated items to assess AR-WF to be used in future research. In summary, our paper aims to address how individuals can actively manage the work-family interface through action regulation, the likely consequences of such action regulation, and how this action regulation can be reliably and validly measured in future research.

\section{Action Regulation Approach and Related Frameworks}

To conceptualize how people actively manage the work-family interface, we draw on ART, which explains how people regulate their behavior by developing, pursuing, and revising goals (Frese \& Zapf, 1994; Zacher \& Frese, 2018). At the core of this conceptualization is the view that humans are self-regulating systems that do not merely passively react to environmental demands, but also actively shape their environment and individual development. ART is a meta-theory that entails key aspects of several self-regulation frameworks (e.g., Carver \& Scheier, 1982; Karoly, 1993; Klein, 1989; Lord et al., 2010) by conceptualizing an action regulation sequence consisting of five phases (Frese \& Zapf, 1994; Zacher \& Frese, 2018): (1) goal development and selection, where individuals either internally generate and self-select goals or adopt assigned goals (e.g., by a supervisor or life partner); (2) orientation or mapping the environment for enabling and hindering factors for goal attainment, where people search for action-relevant information (e.g., opportunities, constraints, resources) by detecting signals related to the probability of successfully attaining their goals; (3) planning for goal attainment, where people develop and select a plan on how to attain their goals, including specifying a set of sub-goals or developing back-up plans in case of occurring problems in goal attainment; (4) monitoring of execution of behaviors and plans during goal pursuit, which involves a comparison between the goal and the actual executed behaviors; and (5) feedback processing during goal pursuit, where people process information about their current performance or progress toward their goals and adapt goals, plans, and/or behaviors, if necessary, to reduce discrepancies between the current state and the desired results of their actions and intended goal progress.

These phases describe action regulation from a theoretical, prescriptive view and thus depict an idealized, schematic sequence. In reality, and from a descriptive perspective, it is possible that individuals engaged in action regulation skip, repeat, and go back to earlier steps, representing a potentially more chaotic and nonsequential process (Frese \& Zapf, 1994; Zacher \& Frese, 2018). These five phases are thus dynamically interrelated and, in combination, represent the degree to which a person can effectively regulate their actions. Action regulation is thus an integrated process consisting of the combined engagement in all five phases. While 
engagement in different action regulation aspects is adaptive and can change over time, individuals are also presumed to show different general tendencies in the extent to which they engage in action regulation behaviors (Frese \& Zapf, 1994; Zacher \& Frese, 2018). Consistent with these theoretical assumptions, we herein focus on the extent to which individuals engage in all aspects of AR-WF at the general level and not on the specific sequential phases or dynamics of action regulation.

ART has some overlap with other self-regulation frameworks, which broadly refer to processes for attaining and maintaining goals (Lord et al., 2010). Self-regulation theories are usually extensions of control theory (Carver \& Scheier, 1982, 2002), which focuses on discrepancy reduction based on a negative feedback loop. However, many selfregulation theories are quite mechanistic, whereas action regulation also includes the notion that people actively develop, select, and revise their goals (e.g., set more challenging goals). In addition, action regulation also emphasizes the importance of information seeking to develop goals and plans, an aspect that is not commonly addressed in most self-regulation theories (Zacher \& Frese, 2018). Another related construct are the selection, optimization, and compensation (SOC) strategies (Freund \& Baltes, 2002). Conceptually, both our measure and SOC are based on an action regulation framework, but SOC comes from a lifespan tradition whereas our measure comes from a work psychology tradition. Both concepts/measures overlap to some extent (see also Zacher et al., 2016): Both include the selection of goals. However, ART is different regarding the goal pursuit strategies (optimization and compensation). The whole ART sequence can be seen to address optimization (i.e., goal pursuit), whereas compensation is not explicitly addressed in ART, as compensation could be an action goal by itself. ART also shares similarities with broader goal setting and goal regulation frameworks (e.g., Bindl et al., 2012; Locke \& Latham, 1990), especially with more recent models of proactive goal regulation, which also encompass processes such as envisioning (i.e., goal development), planning, enacting, and reflecting (Bindl et al., 2012). However, existing conceptualizations and measures of goal regulation focus specifically on goal regulation to complete concrete tasks, for example, at work (Bindl et al., 2012), and not on how people more generally regulate (multiple) goals across life domains.

\section{Action Regulation at the Work-Family Interface}

We propose that ART is a useful framework for conceptualizing how people actively manage the work-family interface, as proposed in the action-theoretical model of work-family balance by Hirschi et al. (2019). According to this framework, people pursue multiple goals across different life domains and use different action regulation strategies that take the various demands, resources, and barriers across life roles into account (Hirschi et al., 2019). A better work-family interface characterized by goal attainment in the work and family domain, reduced work-family conflict, and more work-family enrichment, thus depends on the use of different action regulation behaviors in terms of developing, pursuing, monitoring, and revising goals across the work-family interface. We therefore presume that AR-WF can facilitate the attainment of work and family goals, reduce inter-role conflict, and promote inter-role enrichment. However, to date, no empirical study has investigated the work-nonwork interface from an action regulation perspective. Moreover, we currently lack an understanding of the nomological net of AR-WF, including its theoretical correlates and outcomes.

\section{AR-WF and Related Constructs}

To theoretically clarify the nomological net of AR-WF, we will in the following describe the similarities and differences to a series of related constructs from the self-regulation and work-family literatures. This overview will help to further illustrate what AR-WF is and what it is not, and how it relates to a series of other established constructs in the literature.

Dispositional Self-regulation We conceptualize AR-WF not as a general disposition, but as the behavioral enactment of a set of action regulation behaviors pertaining to the attainment of work and family goals. However, we presume that the engagement in AR-WF is meaningfully related to a more general disposition to engage in self-regulation behaviors. Dispositional self-regulation refers to the degree to which an individual typically engages in self-regulation behaviors (e.g., attention regulation, emotion regulation) across different situations (Luszczynska et al., 2004). Because action regulation shares similarities with self-regulation processes, we presume that people who have a stronger disposition for self-regulation across situations should also engage in more AR-WF. However, the two constructs are not redundant because of the theoretical differences between action regulation and self-regulation, and because AR-WF specifically refers to actions in managing work and family goals, versus a more generalized disposition for exhibiting self-regulation behaviors.

Work and Family Role Commitment We assume that engaging in AR-WF should be significantly related to being highly committed to the work and family role. From a goal perspective, role commitment can be seen as emerging from 
a desire to attain personally valued higher-order goals (i.e., values, identity goals) that are linked to a specific life role (Unsworth et al., 2014). According to goal theory, personally valued higher-order goals should induce people to actively engage in behaviors to attain these goals (Unsworth et al., 2014). Hence, a sense of commitment to the work and family role should lead people to engage in AR-WF in an attempt to achieve personally valued higher-order goals in both life domains. However, AR-WF is conceptually distinct from work and family role commitment as affective-cognitive constructs because action regulation refers to actual behaviors used to attain goals.

Work and Family Goal Regulation Due to the similarities between action regulation and goal regulation, we expect that the two constructs are positively related. Specifically, due to the role-spanning conceptualization of AR-WF, we presume that people who show high levels of AR-WF also show more goal regulation behaviors for work and family goals specifically. However, AR-WF should not be redundant with any of these domain-specific goal regulation behaviors because AR-WF refers to behaviors in pursuit of goals at the work-family interface versus managing goals in the work or family domain in isolation.

Work and Family Role Demands and Resources An important assumption in work-family research is that role demands and resources are key determinants of the work-family interface in terms of experienced conflict or enrichment between roles (ten Brummelhuis \& Bakker, 2012; Voydanoff, 2005). Metaanalytic evidence supports this assumption by confirming that role demands (e.g., role overload) are positively, and resources (e.g., social support at work and home) are negatively related to work-family conflict (Byron, 2005; Ford et al., 2007; Michel et al., 2011). Moreover, meta-analytic results also show that support at work is positively related to work-to-family enrichment and family support is positively related to family-to-work enrichment (Lapierre et al., 2018).

The active attainment, maintenance, and protection of resources for goal attainment is a key element in the conservation of resources theory (Hobfoll et al., 2018) and related work-family frameworks (ten Brummelhuis \& Bakker, 2012). However, while the importance of role demands and resources for work-family conflict and enrichment is broadly accepted, these perspectives do not focus on the active role that people play in managing resources and demands across multiple roles. In contrast, AR-WF does not focus on the extent of demands or resources in different life domains. Instead, action regulation pertains to how people manage goal selection/development and pursuit across life domains, under consideration of various demands and resources. While role demands and resources thus also play a role in action regulation, there is no straightforward connection between degree of engagement in AR-WF and role demands and resources. For example, unfavorable conditions characterized by high role demands and low role resources could increase the need for AR-WF to successfully attain goals in both life role due to increased difficulties to attain goals without deliberate action regulation behaviors. However, unfavorable conditions could also reduce the engagement in action regulation because AR-WF requires resources (e.g., information processing, time, energy) which might not be available when faced with high role demands and low resources. Yet, under favorable conditions (i.e., low demands, high resources) people might also not engage in much deliberate action regulation because goals could be attained without investing much effort.

Hence, AR-WF is less about the extent of available demands and resources as such, but rather about how people adequately select goals, develop action plans, and monitor and revise behavior, under consideration of various degrees of available demands and resources. Thus, consistent with the meta-analytic finding that there is no significant relation between the use of selection-optimization-compensation (SOC) action regulation strategies at work and work demands (Moghimi et al., 2017), we expect that there is no significant relation between the degree which someone engages in AR-WF and existing role demands and resources.

Work-Life Boundary Enactment Although there is a general lack of constructs and measures that address the active role that people play in managing the work-family interface (Hirschi et al., 2019), a notable exception is the concept of boundary management, which deals with how people create and manage boundaries between work and family. Boundary management and the related measurement scales can refer to a range of conceptually distinct constructs, including boundary preferences, boundary control, or boundary permeations (Allen et al., 2014). Because we conceptualize AR-WF as intentional behaviors to manage the work-family interface, examining the conceptual and empirical relation to boundary enactment (Wepfer et al., 2018) seems most relevant. We presume that boundary enactment, in terms of segmentation or integration of work and family roles, can be one specific action strategy that people use to manage work and family role demands. However, boundary enactment is only a part of what would be important for successfully managing work and family roles from an action regulation perspective. Specifically, boundary enactment does not address actions of goal setting, orientation, planning, or monitoring and feedback processing. Moreover, to achieve work and family goals, people could engage in role segmentation, which can reduce negative role spillover, but could also engage in role integration, which allows more work-family enrichment (Allen et al., 2014). There is hence 
no clear theoretical relation between AR-WF and the enactment of specific integration vs. separation boundary behaviors, and we expect that a preference for boundary separation vs. integration enactment is relatively independent from the degree to which an individual engages in AR-WF.

\section{Measurement Development and Validation}

\section{Step 1: Item Development}

We followed a deductive item development approach (Hinkin et al., 1997) with existing research and measurement instruments informing our item development. First, we reviewed the literature on action and self-regulation (e.g., goal setting, planning) to identify existing measurement instruments. We identified 25 instruments with a total of 499 items that covered a broad range of constructs, such as, for example, self-regulation (Brown et al., 1999), planning (Frese et al., 2007), goal setting (Lee et al., 1991), or time management (Macan et al., 1990). We examined the existing measures and identified items that reflected the five postulated phases of action regulation, namely (1) goal setting/ development, (2) orientation, (3) planning, (4) monitoring, and (5) feedback processing.

Next, three of the authors generated six new items for each of the five subdimensions of action regulation (90 items total), informed by existing items that matched each dimension. In keeping with our aim to capture action regulation behaviors to manage work and family, we focused on developing items that reflected actions, not states (e.g., planning not having plans) or traits (e.g., having future time perspective). We created the new items based on guidelines for effective test construction (DeVellis, 2003) to ensure readability, representativeness, and appropriateness. We then jointly discussed the initial item pool to eliminate redundant items, identified those items that best reflected the content domains of the five subdimensions, and adjusted item formulations to maximize comprehensiveness. The resulting item pool consisted of 54 original items, with 10-12 items per subdimension.

\section{Step 2: Content Validity Evaluation}

To assess the content validity of our initial item pool (i.e., the degree to which an item is theoretically linked to the intended construct; Holden \& Jackson, 1979), we used an item-sorting task (Anderson \& Gerbing, 1991). Ten subject matter experts (SMEs), who were PhD students or postdoctoral researchers in work and organizational psychology with expertise in action regulation and work-family research, rated the degree to which the 54 items represent each of the five subdimensions on a scale ranging from 1 (not at all) to
5 (to a very large extent). We retained only those items that generated a mean value above 4.00 , resulting in a reduction of the initial pool with 54 items to 38 items (6 goal development items, 9 mapping items, 9 planning items, 8 monitoring items, and 6 feedback-processing items).

\section{Step 3: Establishing Factorial Structure and Item Reduction}

To establish the factorial structure of our measure and further reduce the number of items, we used item analysis and confirmatory factor analysis (CFA). Our sample consisted of 210 US American full-time employees ( $\geq 35 \mathrm{~h} /$ week), who were recruited online through the Mechanical Turk website. To assess AR-WF, we instructed participants to "Please think about the balance of work and family. We are very interested in learning about how you accomplish what you want in this aspect of your life. Please indicate your agreement with regard to the following statements." Participants were asked to indicate their agreement with the newly developed 38 items on a 5-point Likert-type scale ( $1=$ strongly disagree, $5=$ strongly agree $)$. On average, participants were 36.81 years old $(S D=9.19)$, and $43 \%$ of the sample were female. More than half of the participants held a bachelor degree (56\%), $17.2 \%$ held a master degree, and $17.7 \%$ had completed high school. On average, participants worked $42.48 \mathrm{~h} /$ week $(S D=6.35)$.

First, we conducted item analysis to ensure that each item met specific quality criteria before investigating the properties of the scale (Clark \& Watson, 1995). More specifically, we examined inter-item correlations, means and standard deviations, and skewness and kurtosis of each item. We excluded 3 items that displayed an inter-item correlation $<0.15$. Accordingly, 35 items remained for further analysis.

Second, we used CFA to examine the proposed factorial structure of the 35 items, with each item loading on its theoretically proposed factor (e.g., goal development, monitoring) and allowing for all five latent factors to correlate. This model showed suboptimal fit, $\chi^{2}(550)=1115.0$, $\mathrm{CFI}=0.87, \mathrm{TLI}=0.86, \mathrm{RMSEA}=0.07$, and $\mathrm{SRMR}=0.05$. To improve model fit and further reduce the scale length, we decided to retain only the three most appropriate items per subdimension. In selecting the items, we focused not only on the strength of factor loadings, but also considered item coverage and item redundancy for the final decision. For example, if two items loaded highly on their respective factor, but were largely redundant in content, only one of the items was retained for the final version. As a result, we identified 15 items, 3 items per subdimension (the final items are listed in the Appendix Table 7), which showed excellent fit indices, $\chi^{2}(80)=147.9, \mathrm{CFI}=0.96, \mathrm{TLI}=0.95$, RMSEA $=0.06$, SRMR $=0.04$. 
Table 1 Comparison of different action regulation at the work-family interface (AR-WF) factorial models

\begin{tabular}{|c|c|c|c|c|c|c|}
\hline & \multicolumn{5}{|c|}{ Fit indices } & \multirow{2}{*}{$\begin{array}{l}\text { Difference } \\
\text { to } 5 \text {-factor } \\
\text { model } \\
\Delta \chi^{2}(\Delta d f)\end{array}$} \\
\hline & $d f$ & $C F I$ & $T L I$ & RMSEA & $S R M R$ & \\
\hline \multicolumn{7}{|l|}{ English version (study 1) } \\
\hline 5-factor model & 80 & .98 & .97 & .06 & .02 & \multirow{3}{*}{$68.36(10)^{* * *}$} \\
\hline 1 -factor model & 90 & .95 & .94 & .09 & .03 & \\
\hline 5-factor second-order model & 85 & .97 & .97 & .07 & .03 & \\
\hline \multicolumn{7}{|l|}{ German version (study 2) } \\
\hline 5-factor model & 80 & .98 & .97 & .06 & .02 & \multirow{3}{*}{$68.36(10)^{* * *}$} \\
\hline 1-factor model & 90 & .95 & .94 & .09 & .03 & \\
\hline 5-factor second-order model & 85 & .97 & .97 & .07 & .03 & \\
\hline
\end{tabular}

Note. Results are based on the T1 samples in study $1(N=503)$ and study $2(N=493)$ ${ }^{* * * *} p<.001$

\section{Step 4: Confirming Factor Structure in a New Sample}

To confirm the identified factor structure in another sample, we collected data from 503 US American employees (same sample as used in study 1 in the main manuscript, see respective sample description for details).

We performed a CFA and found that the postulated model with five correlated factors showed good fit (Table 1). A second-order model in which the five factors loaded on a higherorder action regulation factor, and a one-factor model, both showed acceptable model fit, although the one-factor model was significantly worse than the five-factor model. However, as intercorrelations among the five factors were very high $(r=0.75-0.86$, all $p s<0.001)$, and the second-order model also showed good fit, we concluded that an overall action regulation score, representing the average score across the five facets of AR-WF, is an adequate and parsimonious way to assess AR-WF in future analyses.

\section{Step 5: Confirming Boundary-Spanning Construct Validity}

In in a final step, we aimed to confirm that the new measure actually assesses action regulation behaviors across work and family roles and that participants indeed answer the items in reference to both roles-as implied in the scale instruction-vs. a specific role in isolation. We used the same sample as in step 4. In addition to the new measure with the original instruction (see Appendix Table 7), participants completed the same 15 AR-WF items but with different instructions. The work-specific adaptation of the scale included the instruction: "Please think about your work. We are very interested in learning about how you accomplish what you want in this life domain. Please indicate your agreement with regard to the following statements." The family-specific adaptation of the scale included the instruction: "Please think about your family. We are very interested in learning about how you accomplish what you want in this life domain. Please indicate your agreement with regard to the following statements." In addition, we assessed work- and family related proactive goal regulation with the 12 -item proactive goal regulation scale by Bindl et al. (2012) for the work domain (i.e., "Thinking about how you have carried out your core job over the past month, to what extent have you thought about a change-related situation from different angles, before deciding how to act?"), and adapted the same scale to the family domain (i.e., "Thinking about how you have carried out your family activities over the past month, to what extent have you thought about how to better perform your family tasks?"). The answer format was a 5-point scale ranging from 1 (not at all) to 5 (a great deal).

To test the validity of the AR-WF measure and show that it assesses action regulation at the interface of work and family rather than action regulation in work or family in isolation, we examined (1) whether the original AR-WF measure can explain variance in work related proactive goal regulation beyond the family-specific adaptation of the AR-WF measure and (2) whether the original AR-WF measure can explain variance in family related proactive goal regulation beyond the work-specific adaptation of the AR-WF measure. In both cases, we found that the original measure explained significant additional variance (beyond family-specific $\Delta R^{2}=0.07, p<0.001 ; F=49.29, p<0.001$; beyond work-specific $\Delta R^{2}=0.18, p<0.001 ; F=85.19$, $p<0.001)$. The results support the boundary-spanning construct validity of the measure and shows that the scale instructions indeed make people reply to the items in reference to both work and family vs. one role in isolation. 


\section{Study 1: AR-WF and Work-Family Goal Attainment}

In the first study, we aimed to test the empirical relations and construct distinctness of AR-WF regarding dispositional self-regulation, work and family role commitment, and work and family goal regulation. Moreover, we wanted to investigate a key assumption of action regulation theory in the context of the work-family interface: that engagement in action regulation behaviors should facilitate goal attainment (Frese \& Zapf, 1994; Zacher \& Frese, 2018).

\section{AR-WF in Relation to Work and Family Goal Attainment}

Based on ART (Frese \& Zapf, 1994; Zacher \& Frese, 2018), the coordinated use of action regulation behaviors is pivotal to successfully attaining goals. This implies that people who engage in AR-WF should be better able to attain their goals in both the work and family domain (Hirschi et al., 2019). Moreover, because AR-WF is conceptually distinct from other constructs in this area, as we have outlined above, we expect that AR-WF can explain variance in work and family goal attainment beyond related goal-management constructs. Specifically, because AR-WF refers to action regulation behaviors designed to attain goals at the work-family interface, it should explain variance in goal attainment in these two life roles beyond more general dispositions, such as dispositional self-regulation. Moreover, because AR-WF focuses on goal-directed behaviors that should lead to goal attainment, it should relate to work and family goal attainment beyond affective/cognitive variables, such as work and family role commitment. Finally, due to its role-spanning nature, AR-WF should relate to work and family goal attainment beyond domain-specific goal regulation constructs, such as work or family goal regulation more specifically.

Hypothesis 1: AR-WF is positively related to work and family goal attainment, beyond the effects of dispositional self-regulation, work and family role commitment, and work and family goal regulation.

\section{Method}

Participants and Procedure We collected time-lagged data from US American employees who were at least 18 years old and employed for at least $16 \mathrm{~h} /$ week. Participants were recruited with the help of the talk online panel, a professional panel provider that manages a large research-only consumer and business panel, and compensated for participation by the panel provider with an incentive of approximately US $\$ 0.90$ at T1 and US\$0.50 at T2. To ensure high data quality, we screened each participant's response time and response pattern (Meade \& Craig, 2012) and excluded participants with straight-lining response patterns and those who took less than $2 \mathrm{~s}$ on average per item. It took 1464 invites to achieve a total of 538 participants who completed the full survey. Out of these, 35 were screened out because of the above-mentioned criteria. At time 1 (T1) this resulted in a final sample of $N=503$ and we collected data on AR-WF, dispositional self-regulation, work and family role commitment, and work and family goal regulation. Two weeks later, at time 2 (T2; $N=178,35 \%$ response rate), we collected the criterion variables (i.e., work and family goal attainment). At T1, mean age was $43.2(S D=13.06)$ years with $49.3 \%$ women. Most of the participants were married or in a relationship (79.6\%); $48.3 \%$ reported having children living at home with a mean age of the youngest child of $10.1(S D=10.50)$ years. The average work experience was 22.9 years $(S D=13.30)$ with 39.3 weekly work hours $(S D=9.03)$ according to their contract. Participants who also answered at T2 were somewhat older $(M=47.1, S D=12.25, p<0.001)$ and had greater work experience $(M=26.6, S D=13.63, p=0.001)$ compared to the only-T1 sample. The T2 sample did not significantly differ from participants only completing $\mathrm{T} 1$ on any other sociodemographic variables.

Measures To assess $A R-W F$, we used the newly developed and validated 15-item AR-WF measurement scale (see Appendix Table 7). To asses dispositional self-regulation, we used the 7-item self-regulation scale from (Luszczynska et al., 2004), for example, "I can concentrate on one activity for a long time, if necessary"), with answers ranging from 1 (not at all true) to 4 (completely true). For work and family role commitment, we used the life role salience scale from (Amatea et al., 1986), with a 5-point Likert-type response format ranging from 1 (strongly disagree) to 5 (strongly agree). The 5-item occupational role commitment subscale served as a measure of work role commitment (i.e., "I expect to make as many sacrifices as are necessary in order to advance in my work/career"), and we adapted the 5-item marital role commitment subscale to assess family role commitment (i.e., "I expect to commit whatever time is necessary to making my family members feel loved, supported, and cared for"). To measure work- and family-related proactive goal regulation, we used the 12-item proactive goal regulation scale by Bindl et al. (2012) for the work domain (i.e., "Thinking about how you have carried out your core job over the past month, to what extent have you thought about a change-related situation from different angles, before deciding how to act"), and adapted the same scale to the family domain (i.e., "Thinking about how you have carried out your family activities over the past month, to what extent have you thought about how to better perform your family 
tasks"). The answer format was a 5-point scale ranging from 1 (not at all) to 5 (a great deal). We measured work and family goal attainment with the goal attainment scale from (Grant, 2003), which was adapted to assess three goals in each life domain ("List 3 important goals for your work [family]. How would you rate your degree of past success in attaining these work [family] goals?"). Answers ranged from $0 \%$ (no attainment) to $100 \%$ (complete attainment) for each goal, and the average score was taken to represent overall work or family goal attainment.

\section{Results and Discussion}

AR-WF and Related Constructs To test the presumed relations of AR-WF and other constructs, we examined correlations between the overall 15-item AR-WF measure and theoretically related constructs at $\mathrm{T} 1$, and using the entire T1 sample to maximize power of the analyses (Table 2). As expected, AR-WF correlated positively with dispositional self-regulation, work role and family role commitment, and work-related and family-related proactive goal regulation. Controlling for gender, age, marital status, number of children at home, and work hours did not change the pattern of results.

We also tested for discriminant validity using CFA and chi-square $\left(\chi^{2}\right)$ difference tests. We compared a two-factor model comprising one factor for the AR-WF measure and one factor for dispositional self-regulation, work or family role commitment, and work or family proactive goal regulation, respectively, with a one-factor model, where all items from each measure loaded on one common factor. In each case, the two-factor model had a significantly better fit than the one-factor model, supporting the distinctiveness of our new measure from the other constructs (Table 3). To verify the results from the $\chi^{2}$ difference test, we used the Fornell-Larcker criterion (Fornell \& Larcker, 1981), which compares the average variance extracted (AVE) by the AR-WF latent construct from its items, with the squared correlation between the AR-WF measure and otherassumed to be distinct-constructs. This test supported the empirical distinctness of AR-WF from all other constructs, with the AVE (0.69) being higher than the squared correlation between AR-WF and dispositional self-regulation $\left(r^{2}=0.21\right)$, work role commitment $\left(r^{2}=0.22\right)$, family role commitment $\left(r^{2}=0.02\right)$, work-related proactive goal regulation $\left(r^{2}=0.32\right)$, and family-related proactive goal regulation $\left(r^{2}=0.34\right)$.

AR-WF in Relation to Work and Family Goal Attainment To test Hypothesis 1, we regressed work and family goal attainment measured at T2 on AR-WF at T1 among participants who participated at both measurement points. We tested the incremental effects of AR-WF by examining the extent to which AR-WF explained variance in work or family goal attainment beyond dispositional self-regulation, work and family role commitment, and work- and family-related proactive goal regulation (Table 4). Supporting incremental validity beyond other specific constructs, we found that AR-WF explained significant incremental variance for work and family goal attainment beyond every other single construct, except for family goal attainment beyond family goal regulation, largely supporting Hypothesis 1 . However, AR-WF did not explain significant variance beyond the entire set of alternative constructs. Controlling for gender, age, marital status, number of children, and work hours did not change the pattern of results. To further examine the relative contribution of each examined variable for explaining variance in the investigated outcomes, we conducted relative weights analyses (Tonidandel \& LeBreton, 2011) following the procedures of Groemping (2006). The results showed that AR-WF was the most dominant explanatory variable for both outcomes among the set of investigated predictors (Table 4).

In sum, the findings of study 1 show that AR-WF is significantly related to, but empirically distinct from, dispositional self-regulation. Moreover, AR-WF is related to role commitment and proactive goal regulation in both the work and family domain separately, which supports the boundaryspanning nature of the construct. The results also confirm the theoretically presumed nature and uniqueness of AR-WF in relation to other constructs. Finally, we could support the added utility of AR-WF for increased goal attainment in work and family, above and beyond specific related constructs and independent of a range of socio-demographic (e.g., gender) and family variables (e.g., number of children).

\section{Study 2: Cross-Cultural Adaptation and Relation to Work-Family Conflict and Enrichment}

In the second study, we aimed to expand the examination of the nomological net of AR-WF regarding its relation and distinctness from work and family demands and resources and work-life boundary enactment. We also wanted to test whether AR-WF has incremental explanatory utility regarding work-family conflict and enrichment. Moreover, we aimed to adapt the developed measure to another language (i.e., German) to examine the functioning of AR-WF in a different national context. Research has suggested that national contexts can affect experiences at the work-family interface, for example, due to differences in individualism/collectivism values, public policies, or economic factors (Allen et al., 2015). In contrast to the 


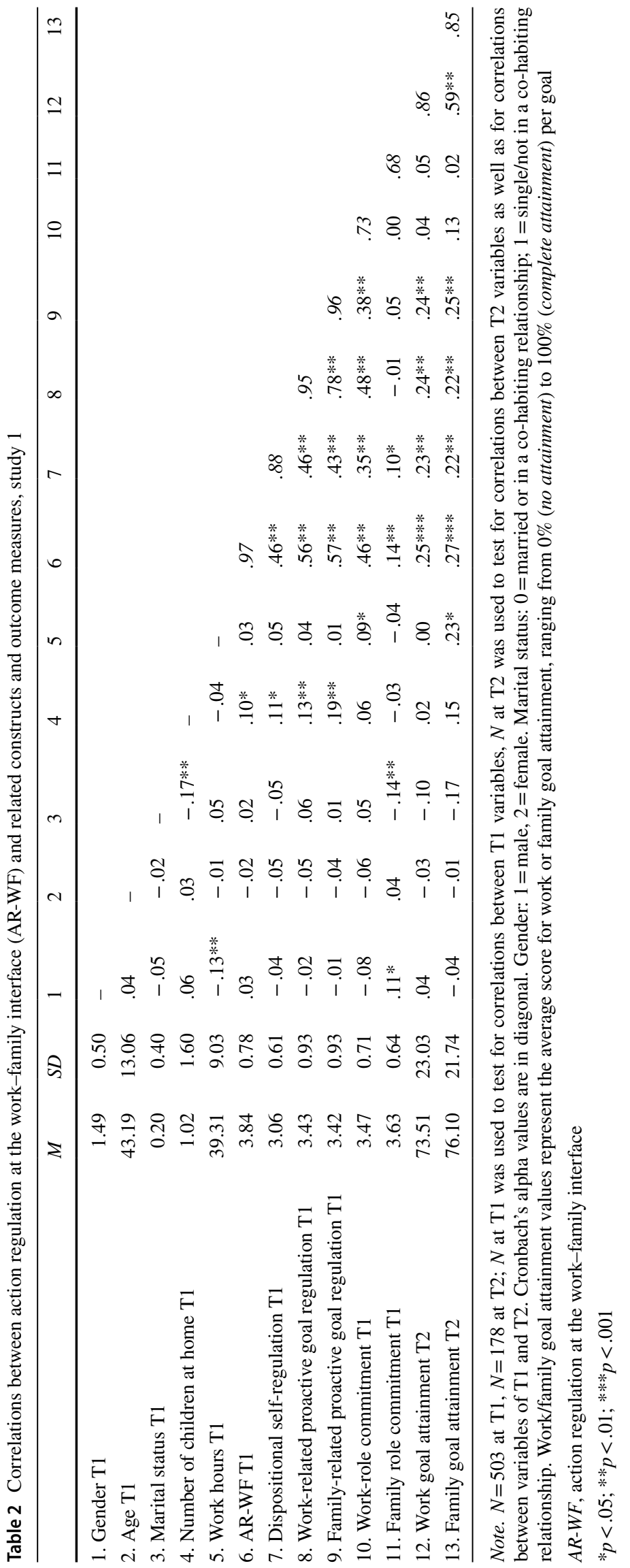


Table 3 Test for discriminant validity between action regulation at the work-family interface (AR-WF) and related constructs, studies 1 and 2

\begin{tabular}{|c|c|c|c|c|c|c|c|c|c|c|c|}
\hline & \multicolumn{10}{|c|}{ Comparison of a 2- vs. 1-factor model } & \multirow[b]{3}{*}{$\Delta \chi^{2}(\Delta d f)$} \\
\hline & \multicolumn{5}{|c|}{ 2-factor model } & \multicolumn{5}{|c|}{ 1-factor model } & \\
\hline & $\overline{d f}$ & $C F I$ & $T L I$ & $R M S E A$ & $\overline{S R M R}$ & $d f$ & $C F I$ & $T L I$ & $R M S E A$ & $\overline{S R M R}$ & \\
\hline$A R-W F$ in relation to... & \multicolumn{11}{|c|}{ Study 1} \\
\hline Dispositional self-regulation & 208 & .97 & .96 & .04 & .03 & 209 & .84 & .83 & .09 & .11 & $715.00(1)^{* * *}$ \\
\hline Work-related proactive goal regulation & 323 & .94 & .94 & .05 & .04 & 324 & .69 & .68 & .12 & .14 & $2634.50(1)^{* * * *}$ \\
\hline Family-related proactive goal regulation & 323 & .94 & .94 & .05 & .04 & 324 & .68 & .65 & .12 & .14 & $2900.30(1)^{* * *}$ \\
\hline Work role commitment & 169 & .96 & .96 & .04 & .05 & 170 & .88 & .90 & .07 & .07 & $411.47(1)^{* * *}$ \\
\hline Family role commitment & 169 & .92 & .91 & .07 & .08 & 170 & .88 & .86 & .08 & .07 & $97.63(1)^{* * * *}$ \\
\hline$A R-W F$ in relation to... & \multicolumn{11}{|c|}{ Study 2} \\
\hline Dispositional self-regulation & 274 & .85 & .84 & .09 & .07 & 275 & .73 & .70 & .12 & .11 & $379.77(1)^{* * *}$ \\
\hline Work demands & 188 & .89 & .88 & .09 & .07 & 189 & .68 & .65 & .15 & .15 & $396.12(1)^{* * *}$ \\
\hline Family demands & 188 & .90 & .89 & .09 & .06 & 189 & .61 & .57 & .17 & .18 & $366.41(1)^{* * *}$ \\
\hline Work support & 151 & .88 & .86 & .11 & .05 & 152 & .70 & .66 & .16 & .13 & $169.27(1)^{* * *}$ \\
\hline Family support & 151 & .91 & .90 & .09 & .05 & 152 & .65 & .60 & .19 & .14 & $321.36(1) * * *$ \\
\hline Work-to-life integration & 169 & .90 & .89 & .09 & .05 & 170 & .72 & .69 & .14 & .13 & $314.29(1)^{* * * *}$ \\
\hline Life-to-work integration & 169 & .90 & .89 & .09 & .05 & 170 & .70 & .66 & .15 & .14 & $269.8(1) * * *$ \\
\hline
\end{tabular}

Note. $A R-W F$ : action regulation at the work-family interface

**** $p<.001$

Table 4 Incremental validity of action regulation at the work-family interface (ARWF) beyond related constructs for work and family goal attainment, study 1

\begin{tabular}{|c|c|c|c|c|c|c|c|c|c|c|}
\hline \multirow[b]{2}{*}{ Predicted outcomes } & $R^{2}$ & $\Delta R^{2}$ & $F$ & $\beta$ & $R W$ & $R^{2}$ & $\Delta R^{2}$ & $F$ & $\beta$ & $R W$ \\
\hline & \multicolumn{5}{|c|}{ Work goal attainment T2 } & \multicolumn{5}{|c|}{ Family goal attainment $T 2$} \\
\hline Disp. self-regulation T1 & & & & .15 & $45 \%$ & & & & .12 & $35 \%$ \\
\hline AR-WF T1 & .08 & $.03^{*}$ & $6.92 * * *$ & $.18^{*}$ & $55 \%$ & .09 & $.04 *$ & $7.41 * * *$ & $.22 *$ & $65 \%$ \\
\hline Work goal regulation $\mathrm{T} 1$ & & & & .11 & $36 \%$ & & & & .11 & $37 \%$ \\
\hline AR-WF T1 & .09 & $.03^{*}$ & $7.84 * * *$ & $.22 *$ & $64 \%$ & .08 & $.03 *$ & $6.64 * *$ & $.20^{*}$ & $63 \%$ \\
\hline Family goal regulation $\mathrm{T} 1$ & & & & .09 & $36 \%$ & & & & .14 & $48 \%$ \\
\hline AR-WF T1 & .09 & $.03^{*}$ & $7.27 * * *$ & $.22 *$ & $64 \%$ & .08 & .02 & $6.83 * * *$ & .17 & $52 \%$ \\
\hline Work commitment $\mathrm{T} 1$ & & & & -.06 & $3 \%$ & & & & .04 & $13 \%$ \\
\hline AR-WF T1 & .07 & $.06 * * *$ & $5.53 * *$ & $.27 * * *$ & $97 \%$ & .08 & $.06 * *$ & $6.47 * *$ & $.26 * *$ & $87 \%$ \\
\hline Family commitment $\mathrm{T} 1$ & & & & .04 & $4 \%$ & & & & .01 & $0 \%$ \\
\hline AR-WF T1 & .06 & $.06 * *$ & $5.29 * *$ & $.25 * *$ & $96 \%$ & .07 & $.07 * * *$ & $5.93 * *$ & $.26 * * *$ & $100 \%$ \\
\hline Disp. self-regulation T1 & & & & .12 & $23 \%$ & & & & .12 & $23 \%$ \\
\hline Work goal regulation $\mathrm{T} 1$ & & & & .12 & $19 \%$ & & & & .00 & $14 \%$ \\
\hline Family goal regulation $\mathrm{T} 1$ & & & & .03 & $18 \%$ & & & & .14 & $29 \%$ \\
\hline Work commitment $\mathrm{T} 1$ & & & & -.10 & $4 \%$ & & & & -.00 & $3 \%$ \\
\hline Family commitment $\mathrm{T} 1$ & & & & .02 & $1 \%$ & & & & .01 & $1 \%$ \\
\hline AR-WF T1 & .11 & .02 & $3.07 * *$ & .17 & $34 \%$ & .09 & .01 & $2.45^{*}$ & .11 & $29 \%$ \\
\hline
\end{tabular}

Note. $N=178$. Results are reported for model $2 ; \Delta R^{2}$ is in comparison to model 1 with only the first listed (i.e., non-AR-WF) construct as predictor

$A R-W F$, action regulation at the work-family interface; $R W$, relative weight of each predictor ${ }^{*} p<.05 ; * * p<.01, * * * p<.001$ context of the USA examined in study 1 , the Germanic culture is lower in individualism, but similar in masculinity (Hofstede, 2001). Moreover, Germany has markedly different work-family policies from the USA in many ways, for example, regarding paid leave for early childcare (OECD, 2017). Hence, examining AR-WF across these two contexts adds insight into the cross-cultural generalizability and functionality of AR-WF. 


\section{AR-WF in Relation to Work-Family Conflict and Enrichment}

We expect that AR-WF should relate to decreased work-family conflict and increased work-family enrichment. Because we conceptualize AR-WF as the active regulation of work and family goals to attain goals across both life domains, we expect that people who are more engaged in AR-WF should better be able to diminish or avoid goal conflict (resulting in reduced work-family conflict) and create or use goal facilitation across work and family goals (resulting in increased work-family enrichment). This could occur because AR-WF entails mapping the environment for resources and barriers related to goal attainment, as well as monitoring and, if necessary, revising goals, plans, and/or actions based on feedback during goal pursuit. This active management of goals across work and family should help avoid goals that lead to goal conflict, and instead pursue goals that show facilitative linkages to other goals. Moreover, AR-WF should help to better allocate and develop resources for goal attainment, and to adapt (or abandon) goals if necessary, leading to less work-family goal conflict and more goal facilitation. Because AR-WF incudes the consideration of work and family goals, we moreover expect that its effects on work-family conflict and enrichment should occur on both the work-tofamily and the family-to-work direction of this interface.

To establish incremental utility of AR-WF, we test the effects on work-family conflict and enrichment beyond dispositional self-regulation, work-family demands and resources, and work-life boundary enactment. Due to its conceptual differences, we assume that AR-WF explains variance in work-family conflict and enrichment beyond these other constructs.

Hypothesis 2: AR-WF is (a) negatively related to workfamily conflict, and (b) positively related to work-family enrichment, beyond dispositional self-regulation, workfamily demands and resources, and work-life boundary enactment.

\section{Method}

Participants and Procedure We collected time-lagged data from a sample of German working adults who were recruited using the same online research panel provider as in study 1. Participants had to be at least 18 years old and be employed for a minimum of $16 \mathrm{~h} /$ week. At T1, we collected sociodemographic data, AR-WF, work and family demands and resources, and work-life boundary enactment. Three months later, at T2, we measured the outcome variables of work-family conflict and enrichment. Respondents received an incentive of $2.00 €$ at $\mathrm{T} 1$ and $1.50 €$ at $\mathrm{T} 2$ for their participation. We excluded all participants not meeting the inclusion criteria regarding age and working hours, respondents who did not complete the full survey, and checked again for data quality in terms of stream-lining and response speed (i.e., less than 2 s/item on average) (Meade \& Craig, 2012). At T1, 555 participants participated in the survey, which resulted in $N=493$ after data cleaning and $N=297(60 \%)$ participated at $\mathrm{T} 2$.

At T1, the average age of participants was 46.99 years $(S D=11.22)$, with $51.30 \%$ female participants. People were employed in a large variety of industries, had an average work experience of 25.27 years $(S D=12.87)$, and an average organizational tenure of 13.92 years $(S D=11.60)$. Their mean working time was $35.82 \mathrm{~h} /$ week $(S D=8.20)$, and $70.40 \%$ of participants had a full-time contract. About half of the participants $(45.00 \%)$ were married, and $37.40 \%$ had one or more children living in their home. The average age of the youngest child was 6.22 years $(S D=8.99)$. The T2 sample did not significantly differ from participants only completing $\mathrm{T} 1$ on any sociodemographic characteristic.

Measures To measure $A R-W F$, we translated the AR-WF scale into German. All items were translated by two of the authors in a blind parallel translation, and existing differences were discussed and reconciled with a third author. The same procedure was used for all other scales in this study for which no German version was available.

Dispositional self-regulation was assessed with the same scale as in study 1 . We assessed work and family demands with six items each (e.g., "I cannot ever seem to catch up at home") by Thiagarajan et al. (2006) based on the role overload scale by Reilly (1982) on a seven-point response scale from 1 (never) to 7 (always). To assess work and family resources, we measured work and family support with fouritems each (e.g., "I can talk about problems with my family") from the Multidimensional Scale of Perceived Social Support by (Zimet et al., 1988) on a response scale from 1 (don't agree at all) to 7 (completely agree). We measured work-life boundary enactment using the German version of the boundary enactment scale (Wepfer et al., 2018), consisting of 10 bipolar statements with 5 items measuring work-tolife integration (e.g., "I never take work home" vs. "I often take work home"), and 5 items measuring life-to-work integration (e.g., "I never think about nonwork issues while I am at work" vs. "I often think about nonwork issues while I am at work"). Participants had to indicate which statement better represented their boundary enactment on a scale from 1 to 7 , with higher scores indicating more integration enactment. Family-to-work conflict and work-to-family conflict were both measured with the six-item German version by Seiger and Wiese (2009) of the work-family interference scale from Carlson and Frone (2003), with a 5-point response format 
ranging from 1 (never) to 5 (always). We assessed familyto-work enrichment and work-to-family enrichment using the 5-item positive home-work interaction, and the 5-item positive work-home interaction, respectively, subscales of the SWING questionnaire (Geurts et al., 2005) with the German version by Nitzsche et al. (2013) on a 4-point scale ranging from 1 (never) to 4 (always).

\section{Results and Discussion}

\section{Preliminary Analyses}

Confirming Factor Structure of the German AR-WF Scale We performed a CFA with the whole T1 sample. Similar to the English version, the German version showed good fit indices (Table 1). The one-factor model had a significantly worse fit than the five-factor model, but the second-order model also showed good fit. The factor loadings of the 15 items on the general AR-WF score were high, and all larger than 0.64 . As with the English version, the five factors had high intercorrelations ( $r=0.59-0.77$, all $p \mathrm{~s}<0.001)$, and the general AR-WF factor showed high reliability with Cronbach's $\alpha=0.95$.

We further examined measurement invariance between the English (using data from study 2, T1) and German version of the AR-WF measure. We found support for configural invariance of the five-factor model, the five-factor second-order model, but not the one-factor model. Metric invariance was supported for the five-factor model only. No model reached scalar invariance (full results are available upon request). These results suggest that AR-WF shows the same factorial structure across US and German samples, and that the five components of AR-WF have equal substantive meaning. However, the relative importance of the five components for overall AR-WF and levels of AR-WF seem to differ across the cultural background of the samples.

Discriminant Validity Correlations among all assessed constructs are reported in Table 5. We applied CFA among the whole T1 sample to test discriminant validity of the German AR-WF measure from dispositional self-regulation, work/ family role demands and supports, and the two directions of work-life boundary integration enactment using chi-square $\left(\chi^{2}\right)$ difference tests and the same procedure as in Study 1. The results showed a significantly better fit for models that distinguish the one-factor AR-WF from dispositional selfregulation, work/family role demands, work/family support, and the work-life boundary enactment constructs, compared to a single-factor model (Table 3). To validate these results, we again used the Fornell-Larcker criterion. The AVE of the German AR-WF measure was 0.58, and thus higher than the squared correlation between AR-WF and dispositional self-regulation $\left(r^{2}=0.18\right)$, work demands $\left(r^{2}=0.00\right)$, family demands $\left(r^{2}=0.00\right)$, work support $\left(r^{2}=0.06\right)$, family support $\left(r^{2}=0.11\right)$, work-to-life integration $\left(r^{2}=0.03\right)$, and life-to-work integration $\left(r^{2}=0.00\right)$. Confirming the finding from study 1, AR-WF was positively related to dispositional self-regulation $(r=0.35, p<0.01)$. Furthermore, as expected AR-WF was not correlated with work demands $(r=0.04, p=0.52)$ or family demands $(r=0.06, p=0.31)$ but weakly related to more work support $(r=0.29, p<0.01)$ and family support $(r=0.33, p<0.01)$, contrary to expectation. Finally, largely confirming our assumption that AR-WF is not systematically related to a specific boundary enactment strategy, AR-WF was not significantly correlated with life-to-work integration enactment $(r=0.01, p=0.88)$, and only weakly related to work-to-life integration enactment $(r=0.16 ; p<0.01)$.

\section{AR-WF in Relation to Work-Family Conflict and Enrichment}

To test Hypothesis 2, we regressed both directions of work-family conflict and work-family enrichment at T2 on AR-WF measured at T1. Contrary to our expectation, AR-WF was positively related to work-to-family conflict $(\beta=0.20 ; p<0.001)$, but not significantly related with family-to-work conflict $(\beta=0.09 ; p=0.11)$, refuting Hypothesis 2 a. As expected, AR-WF was positively related to both directions of enrichment (family-to-work, $\beta=0.37$, and work-to-family, $\beta=0.24$, both $p$ s $<0.001$ ), confirming Hypothesis $2 \mathrm{~b}$. Controlling for gender, age, and children at home did not change the pattern of results.

To assess incremental validity, we analyzed the explained variance of AR-WF in both directions of work-family conflict and enrichment beyond dispositional self-regulation, work/family role demands and resources, and the two directions of work-life boundary enactment (Table 6). AR-WF explained significant variance $\left(\Delta R^{2}=0.01\right.$ to 0.14$)$ beyond dispositional self-regulation in all outcomes except for family-to-work conflict, and beyond work/family role demands and resources as well as work-to-life and life-to-work integration, in all outcomes. AR-WF also explained a small but significant amount of variance in work-to-family conflict, as well as in family-to-work enrichment, and work-to-family enrichment beyond all other variables combined. Controlling for gender, age, and number of children at home did not change the pattern of results. We also again conducted relative weights analyses to examine the relative importance of each variable for explaining variance in the examined outcomes. The results showed that for enrichment, WF-AR was a dominant explanatory variable. However, for conflict, other variables had more explanatory value. 


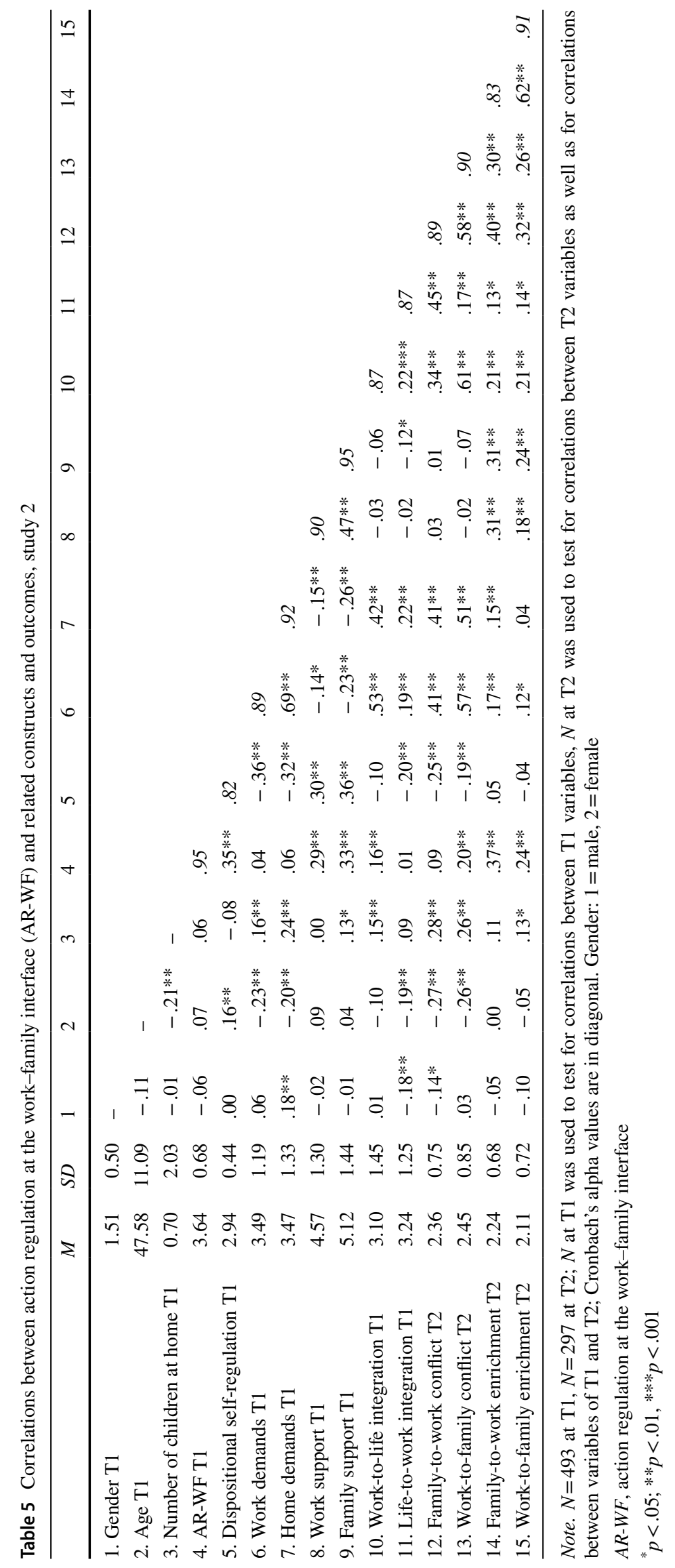


Table 6 Incremental validity of action regulation at the work-family interface (AR-WF) beyond dispositional self-regulation, work/family role demands and resources, and the two directions of work-life boundary enactment for work-family outcomes, study 2

\begin{tabular}{|c|c|c|c|c|c|c|c|c|c|c|}
\hline & $R^{2}$ & $\Delta R^{2}$ & $F$ & $\beta$ & $R W$ & $R^{2}$ & $\Delta R^{2}$ & $F$ & $\beta$ & $R W$ \\
\hline Predicted outcomes & \multirow{2}{*}{\multicolumn{3}{|c|}{ Family-to-work conflict $T 2$}} & & & \multicolumn{5}{|c|}{ Work-to-family conflict $T 2$} \\
\hline Disp. self-regulation T1 & & & & $-.21 * * *$ & $57 \%$ & & & & $-.22 * * *$ & $29 \%$ \\
\hline AR-WF T1 & .04 & $.03 * *$ & $6.67^{* * *}$ & $.19^{* *}$ & $43 \%$ & .08 & $.07 * * *$ & $11.95^{* * * *}$ & $.30 * * *$ & $71 \%$ \\
\hline Work demands T1 & & & & $.41 * * *$ & $96 \%$ & & & & $.56^{* * *}$ & $90 \%$ \\
\hline AR-WF T1 & .17 & .01 & $30.45^{* * *}$ & .08 & $4 \%$ & .35 & $.03 * * *$ & $79.07 * * *$ & $.17 * * *$ & $10 \%$ \\
\hline Home demands $\mathrm{T} 1$ & & & & $.41^{* * *}$ & $96 \%$ & & & & $.50 * * *$ & $89 \%$ \\
\hline AR-WF T1 & .18 & .01 & $30.97 * * *$ & .07 & $4 \%$ & .29 & $.03 * * *$ & $58.77 * * *$ & $.17 * * *$ & $11 \%$ \\
\hline Work resources $\mathrm{T} 1$ & & & & .01 & $6 \%$ & & & & -.08 & $7 \%$ \\
\hline AR-WF T1 & .01 & .01 & 1.28 & .09 & $94 \%$ & .04 & $.04 * * *$ & $6.69^{* * *}$ & $.22 * * *$ & $93 \%$ \\
\hline Home resources $\mathrm{T} 1$ & & & & -.02 & $3 \%$ & & & & $-.15^{*}$ & $22 \%$ \\
\hline AR-WF T1 & .01 & .01 & 1.16 & .09 & $97 \%$ & .06 & $.05^{* * *}$ & $8.78^{* * * *}$ & $.24 * * *$ & $78 \%$ \\
\hline Work-to-life integration $\mathrm{T} 1$ & & & & $.33^{* * *}$ & $96 \%$ & & & & $.60^{* * *}$ & $94 \%$ \\
\hline AR-WF T1 & .12 & .00 & $19.03 * * *$ & .04 & $4 \%$ & .38 & $.01 *$ & $91.30 * * *$ & $.10^{*}$ & $6 \%$ \\
\hline Life-to-work integration $\mathrm{T} 1$ & & & & $.45^{* * * *}$ & $96 \%$ & & & & $.17 * *$ & $44 \%$ \\
\hline AR-WF T1 & .21 & .01 & $39.02 * * *$ & .09 & $4 \%$ & .07 & $.04 * * *$ & $10.55 * * *$ & $.19^{* * *}$ & $56 \%$ \\
\hline Predicted outcomes & Fam & $o$-work c & ct $T 2$ & & & Wor & family ce & $t T 2$ & & \\
\hline Disp. self-regulation $\mathrm{T} 1$ & & & & -.11 & $3 \%$ & & & & -.10 & $1 \%$ \\
\hline Work demands T1 & & & & $.17^{*}$ & $19 \%$ & & & & $.21^{* *}$ & $28 \%$ \\
\hline Home demands $\mathrm{T} 1$ & & & & $.21^{* *}$ & $21 \%$ & & & & $.18^{* *}$ & $21 \%$ \\
\hline Work resources $\mathrm{T} 1$ & & & & .05 & $1 \%$ & & & & .04 & $0 \%$ \\
\hline Home resources $\mathrm{T} 1$ & & & & $.16^{* *}$ & $3 \%$ & & & & .02 & $1 \%$ \\
\hline Work-to-life integration $\mathrm{T} 1$ & & & & .09 & $11 \%$ & & & & $.41 * * *$ & $43 \%$ \\
\hline Life-to-work integration $\mathrm{T} 1$ & & & & $.36^{* * * *}$ & $40 \%$ & & & & .00 & $2 \%$ \\
\hline AR-WF T1 & .36 & .00 & $20.17 * * *$ & .04 & $1 \%$ & .49 & $.01^{* *}$ & $34.05^{* * *}$ & $.14^{* *}$ & $5 \%$ \\
\hline Predicted outcomes & \multicolumn{5}{|c|}{ Family-to-work enrichment $T 2$} & \multicolumn{5}{|c|}{ Work-to-family enrichment T2 } \\
\hline Disp. self-regulation T1 & & & & -.07 & $6 \%$ & & & & -.08 & $6 \%$ \\
\hline AR-WF T1 & .14 & $.13 * * *$ & $23.76^{* * *}$ & $.40 * * *$ & $94 \%$ & .06 & $.06 * * *$ & $9.75^{* * *}$ & $.28 * * *$ & $94 \%$ \\
\hline Work demands $\mathrm{T} 1$ & & & & $.16^{* * *}$ & $17 \%$ & & & & .11 & $18 \%$ \\
\hline AR-WF T1 & .16 & $.16 * * *$ & $28.33^{* * *}$ & $.36 * * *$ & $83 \%$ & .07 & $.06 * * *$ & $10.78 * * *$ & $.24 * * *$ & $82 \%$ \\
\hline Home demands $\mathrm{T} 1$ & & & & $.13^{*}$ & $13 \%$ & & & & .03 & $2 \%$ \\
\hline AR-WF T1 & .15 & $.13 * * *$ & $26.66^{* * *}$ & $.36 * * *$ & $87 \%$ & .06 & $.06 * * *$ & $8.99 * * *$ & $.24 * * *$ & $98 \%$ \\
\hline Work resources $\mathrm{T} 1$ & & & & $.22 * * *$ & $38 \%$ & & & & $.13^{*}$ & $33 \%$ \\
\hline AR-WF T1 & .18 & $.09 * * *$ & $32.25^{* * *}$ & $.31 * * *$ & $62 \%$ & .07 & $.04 * * *$ & $11.29 * * *$ & $.20 * * *$ & $67 \%$ \\
\hline Predicted outcomes & \multicolumn{5}{|c|}{ Family-to-work enrichment $T 2$} & \multicolumn{5}{|c|}{ Work-to-family enrichment $T 2$} \\
\hline Home resources $\mathrm{T} 1$ & & & & $.21 * * *$ & $39 \%$ & & & & $.19^{* *}$ & $52 \%$ \\
\hline AR-WF T1 & .17 & $.08^{* * *}$ & $30.66^{* * *}$ & $.30 * * *$ & $61 \%$ & .09 & $.03 * *$ & $13.80 * * *$ & $.17^{* *}$ & $48 \%$ \\
\hline Work-to-life integration $\mathrm{T} 1$ & & & & $.15^{* *}$ & $20 \%$ & & & & $.18^{* * *}$ & $44 \%$ \\
\hline AR-WF T1 & .16 & $.12 * * *$ & $27.59^{* * * *}$ & $.35^{* * *}$ & $80 \%$ & .01 & $.04 * *$ & $14.17 * * *$ & $.21 * * *$ & $56 \%$ \\
\hline Life-to-work integration $\mathrm{T} 1$ & & & & $.13^{*}$ & $11 \%$ & & & & $.13^{*}$ & $24 \%$ \\
\hline AR-WF T1 & .15 & $.14 * * *$ & $26.29 * *$ & $.37 * * *$ & $89 \%$ & .07 & $.06^{* *}$ & $11.79 * * *$ & $.24 * * *$ & $76 \%$ \\
\hline Disp. self-regulation $\mathrm{T} 1$ & & & & -.11 & $3 \%$ & & & & -.12 & $3 \%$ \\
\hline Work demands $\mathrm{T} 1$ & & & & .11 & $6 \%$ & & & & .09 & $5 \%$ \\
\hline Home demands $\mathrm{T} 1$ & & & & .08 & $5 \%$ & & & & -.08 & $2 \%$ \\
\hline Work resources $\mathrm{T} 1$ & & & & $.19 * *$ & $20 \%$ & & & & .08 & $10 \%$ \\
\hline Home resources T1 & & & & $.23 * * *$ & $24 \%$ & & & & $.22^{* *}$ & $29 \%$ \\
\hline Work-to-life integration $\mathrm{T} 1$ & & & & .07 & $7 \%$ & & & & $.16^{*}$ & $19 \%$ \\
\hline Life-to-work integration T1 & & & & .09 & $4 \%$ & & & & .11 & $9 \%$ \\
\hline AR-WF T1 & .27 & $.05 * * *$ & $12.98 * * *$ & $.27 * * *$ & $30 \%$ & .16 & $.02 * *$ & $6.54 * * *$ & $.17 * *$ & $22 \%$ \\
\hline
\end{tabular}

Note. $N=297$. Standardized results are reported for model 2. $\Delta R^{2}$ is in comparison to model 1, with only the first listed (i.e., non-AR-WF) construct as predictor

$A R-W F$, action regulation at the work-family interface; $R W$, relative weight of each predictor

${ }^{*} p<.05 ; * * p<.01 ; * * * p<.001$ 
In sum, the results of study 2 show that AR-WF is independent of role demands but positively related to increased role resources. Possibly, because AR-WF requires the investment of resources in terms of executive functions, time, and energy, having social support at work and home can facilitate this active engagement. We also showed that AR-WF is largely independent of specific boundary enactment behaviors, which supports the assumption that boundary enactment can be used in different ways when engaging in AR-WF. Finally, the study provided some insight into the utility of AR-WF due to its positive relation to work-family enrichment, beyond a series of other relevant constructs and irrespective of sociodemographic and family variables. This partially supports the positive effects of AR-WF on the work-family interface, and the incremental utility of the construct beyond a general disposition for self-regulation, role demands and supports, and boundary management behaviors. However, contrary to our expectations, we found no support for the assumption that AR-WF would reduce work-family conflict. This calls for further inquiries into the ways in which action regulation behaviors could reduce, but potentially also enhance, experienced conflict between life domains.

\section{General Discussion}

Despite broad agreement among researchers that individual actions are important to the successful management of work and family roles (Grawitch et al., 2010; Hirschi et al., 2019; Marks \& MacDermid, 1996; Voydanoff, 2005), there has been relatively little empirical work on how people actively manage the work-family interface. In our study, we built on ART (Frese \& Zapf, 1994; Zacher \& Frese, 2018) to advance this line of research and offer several new insights into the active ways in which individuals can manage the work-family interface.

The reported studies help to address the issue that many existing theoretical models allude to the importance of role management strategies, but often fail to provide a more specific account of the concrete behaviors that people can undertake to manage life roles (Grawitch et al., 2010; Marks \& MacDermid, 1996; Voydanoff, 2005). Our studies are based on the theoretical assumption that people can use a set of behavioral strategies based on ART for this purpose. We aimed to advance knowledge on the nature and nomological net of AR-WF by examining theoretical predictors, correlates, and outcomes. As we could show, AR-WF is related to, but empirically distinct from, several relevant self-regulation and goal management constructs, as well as from work and home resources and support as well as different boundary enactment strategies. Our studies thereby support the added value of examining AR-WF beyond other frequently examined constructs in the work-family literature (Allen et al., 2014; Shockley et al., 2017), to gain a more comprehensive understanding of the active role that people play in managing work and nonwork roles.

Another aim was to examine the likely consequences of AR-WF. Supporting a key assumption of ART (Frese \& Zapf, 1994; Zacher \& Frese, 2018), we found that people who engage in more AR-WF were more successful in attaining their goals in both work and family. Moreover, we were able to demonstrate the role-spanning effects of AR-WF beyond role-specific goal regulation. Supporting theoretical assumptions from the work-family balance action regulation model (Hirschi et al., 2019), this shows that if people engage in action regulation behaviors that consider the work and family role, they can reap benefits for goal attainment that go beyond focusing on goal management in a specific role only. Supporting the broad relevance of AR-WF, we also confirmed that the obtained results were not affected by sociodemographic (i.e., gender, age) and family factors (i.e., number of children at home).

We were further able to show that AR-WF is meaningfully related to experiencing work-family enrichment. As our study suggests, people who engage in AR-WF seem to be better able to use or create facilitative linkages across work and family goals, which enhances their experience of work-family enrichment. However, contrary to our expectations, AR-WF was positively related to work-to-family conflict, and unrelated to family-to-work conflict. This implies that even if people are actively using various action strategies to manage work and family, this does not necessarily reduce the experience of role conflicts. It is notable that our studies thus indicate that AR-WF seems to facilitate goal attainment in both work and family roles, but can simultaneously go along with an increased, rather than reduced, experience of work-family conflict. One possible explanation for this is somewhat contradictory finding is that engaging in AR-WF consumes resources (e.g., executive processes, time, energy) in both work and family roles. As such, even if goals in each domain are better attained due to this active goal management approach, this process might also highlight conflicts between work and family goals due to limited resources and resource drain. As our results suggest, people who are more engaged in AR-WF are generally also more committed to work and family roles, which might attenuate increased resource drain and conflict across roles (Byron, 2005; Shockley et al., 2017). Heightened experiences of work-family conflict could thus result from being actively engaged in AR-WF, even though the overall effects of AR-WF on meeting role demands are positive. Future research is needed to provide more insight into this issue.

A final contribution of our research is that we applied a new measure to assess the theoretically proposed five action regulation phases by ART of goal selection and 
development, orientation, planning, monitoring, and feedback processing (Frese \& Zapf, 1994). As such, we provide new insights for ART in general because we could show that these five components of action regulation are highly related, and that people who engage in one aspect of action regulation are also likely to engage in the other aspects. Our results thus suggest that although the five phases of action regulation proposed by ART can be empirically differentiated and reliably measured, they seem to represent a combined approach to action regulation rather than clearly distinct strategies. This finding is consistent with metaanalytic results showing that theoretically different aspects of self-regulation are often highly correlated and difficult to empirically clearly distinguish (Sitzmann \& Ely, 2011). It also confirms theoretical assumptions by ART that successful action regulation consists not of the singular strategies in isolation, but emerges from the combined use of the five action regulation phases (Frese \& Zapf, 1994; Zacher \& Frese, 2018). Our studies contribute to this literature by providing a set of validated items to assess the general extent to which someone engages in such action regulation behaviors. The herein developed and evaluated measure can be applied in future research to advance theoretical and empirical knowledge on the active role that people play in managing work and nonwork roles.

\section{Limitations and Future Research}

One limitation of our study is that we only collected selfreport measures. The herein reported constructs can all be validly assessed by self-report because we focus on psychological variables (e.g., AR-WF, self- and goal regulation constructs, perceived goal attainment, and experiences of work-family conflict and enrichment). Moreover, we applied time-lagged designs to minimize common method bias between AR-WF and the assessed outcomes. However, future studies could evaluate the extent to which spouse and supervisor ratings correspond to self-rated AR-WF, and how self-report action relates to work and family outcomes as assessed by others, such as job performance or marital satisfaction.

Another limitation is that we are not able to make inferences about causality. As such, we cannot definitively confirm that goal attainment and role conflict and enrichment are outcomes of AR-WF. It could also be possible, for example, that people who experience more work-family conflict engage in more AR-WF as a reaction to these experienced conflicts, or that a sense of goal attainment and role enrichment provides resources and motivation to engage in more AR-WF. Future studies could examine such questions of causality and potential mutual effects between action regulation and other constructs with experimental designs (e.g., intervention studies) or cross-lagged studies comprising several measurement waves. Relatedly, it was not possible to, and we also did not aim to, examine potential temporal dynamics in action regulation, where engagement in specific phases might affect the engagement in subsequent phases over time. Future research could assess such dynamics but must keep in mind that the phases might not unfold in a clear sequence and might represent a rather chaotic process (Zacher \& Frese, 2018).

Finally, although we investigated a range of constructs in the nomological net of AR-WF, future research should expand this examination. Other variables of interests related to AR-WF would be, for example, various role performance (e.g., job performance) or well-being outcomes (e.g., exhaustion, life satisfaction). Likewise, other antecedents and correlates could be examined to gain a better understanding of the nature of AR-WF. For example, personal resources, such as self-esteem, or contextual resources, such as family supportive work culture, might be important facilitators of AR-WF that future studies could examine. Relatedly, we focused on action regulation for work and family specifically, but future research could adapt our theoretical approach and measurement to examine work in relation to other life roles (e.g., leisure, community service), or the work-life (nonwork) interface more generally. Moreover, while we were able to test the relation and incremental validity of WF-AR to a range of related constructs, other constructs of life-management and action regulation could be examined in relation to WF-AR in future studies, for example SOC strategies (Freund \& Baltes, 2002). Future research could theoretically and empirically more closely examine such areas of overlap and distinction, specifically in the domain of work-family action regulation (Baltes \& Heydens-Gahir, 2003). Moreover, future research could also employ a context-free measure of action regulation and examine how "general" action regulation relates to different outcomes beyond action regulation in specific contexts.

\section{Conclusions}

Based on ART, we conceptualized the management of work and family roles as the engagement in a combined set of five action regulation strategies (i.e., goal development, orientation, planning, monitoring, and feedback processing). Our study sheds light on the active role that people play in managing various role demands at the work-nonwork interface, including the potential correlates and outcomes of such behaviors. By providing a novel perspective and a validated scale that measures AR-WF, our study should provide a useful addition to the work-family literature to increase our understanding of how individuals can actively achieve a better work-nonwork interface. 


\section{Appendix}

Allen, T. D., French, K. A., Dumani, S., \& Shockley, K. M. (2015). Meta-analysis of work-family conflict mean differences: Does

Table 7 Final items of the action regulation at the work-family interface (AR-WF) scale

Instructions: "Please think about the balance of work and family. We are very interested in learning about how you accomplish what you want in this aspect of your life. Please indicate your agreement regarding the following statements."

Goal development/selection

Orientation/mapping

Planning

Monitoring

Feedback processing
I set clear goals for what I would like to attain

I set myself challenging yet achievable goals

I develop goals that are attractive to me

I reflect on how to use my personal resources to attain my goals

I consider factors that may hinder me from attaining my goals

I check my surroundings for opportunities that help me attain my goals

I carefully plan what I need to do in order to achieve my goals

I think about different options to achieve my goals

I develop plans that I can adjust if things do not work out as originally planned I compare my actual behavior to my initial plans

I keep track of whether what I am doing corresponds to my original plans

I evaluate how well I am pursuing my initial plans

I evaluate the outcomes of my behavior in relation to my goals

I use information to evaluate my progress toward achieving my goals

I assess how fast I am making progress toward my goals

Note. Answers are provided on a 5-point Likert-type response scale $(1=$ strongly disagree, $2=$ disagree, $3=$ neither agree nor disagree, $4=$ agree, $5=$ strongly agree .

Acknowledgements We would like to thank Jeff Greenhaus and Michael Frese for their valuable feedback to an earlier version of this paper.

Funding Open Access funding provided by Universität Bern. This research was supported by a research grant awarded to Andreas Hirschi by the Swiss State Secretariat for Education, Research and Innovation (SERI). The funding source had no involvement in study design, in the collection, analysis and interpretation of data, in the writing of the report, or in the decision to submit the article for publication.

Open Access This article is licensed under a Creative Commons Attribution 4.0 International License, which permits use, sharing, adaptation, distribution and reproduction in any medium or format, as long as you give appropriate credit to the original author(s) and the source, provide a link to the Creative Commons licence, and indicate if changes were made. The images or other third party material in this article are included in the article's Creative Commons licence, unless indicated otherwise in a credit line to the material. If material is not included in the article's Creative Commons licence and your intended use is not permitted by statutory regulation or exceeds the permitted use, you will need to obtain permission directly from the copyright holder. To view a copy of this licence, visit http://creativecommons.org/licenses/by/4.0/.

\section{References}

Allen, T. D., Cho, E., \& Meier, L. L. (2014). Work-family boundary dynamics. Annual Review of Organizational Psychology and Organizational Behavior, 1(1), 99-121. https://doi.org/10.1146/ annurev-orgpsych-031413-091330. national context matter? Journal of Vocational Behavior, 90 , 90-100. https://doi.org/10.1016/j.jvb.2015.07.006.

Allen, T. D., Johnson, R. C., Saboe, K. N., Cho, E., Dumani, S., \& Evans, S. (2012). Dispositional variables and work-family conflict: A meta-analysis. Journal of Vocational Behavior, 80(1), 17-26. https://doi.org/10.1016/j.jvb.2011.04.004.

Amatea, E. S., Cross, E. G., Clark, J. E., \& Bobby, C. L. (1986). Assessing the work and family role expectations of career-oriented men and women - The life role salience scales. Journal of Marriage and the Family, 48(4), 831-838. https://doi.org/ $10.2307 / 352576$.

Anderson, J. C., \& Gerbing, D. W. (1991). Predicting the performance of measures in a confirmatory factor analysis with a pretest assessment of their substantive validities. Journal of Applied Psychology, 76, 732-740. https://doi.org/10.1037/ 0021-9010.76.5.732.

Baltes, B. B., \& Heydens-Gahir, H. A. (2003). Reduction of workfamily conflict through the use of selection, optimization, and compensation behaviors. Journal of Applied Psychology, 88(6), 1005-1018. https://doi.org/10.1037/0021-9010.88.6.1005.

Bindl, U. K., Parker, S. K., Totterdell, P., \& Hagger-Johnson, G. (2012). Fuel of the self-starter: How mood relates to proactive goal regulation. Journal of Applied Psychology, 97(1), 134-150. https://doi.org/10.1037/a0024368.

Brown, J. M., Miller, W. R., \& Lawendowski, L. A. (1999). The SelfRegulation Questionnaire. In L. VandeCreek \& T. L. Jackson (Eds.), Innovations in clinical practice: A source book (Vol. 17, pp. 281-289). Professional Resource Press.

Byron, K. (2005). A meta-analytic review of work-family conflict and its antecedents. Journal of Vocational Behavior, 67(2), 169-198. https://doi.org/10.1016/j.jvb.2004.08.009.

Carlson, D. S., \& Frone, M. R. (2003). Relation of behavioral and psychological involvement to a new four-factor conceptualization 
of work-family interference. Journal of Business and Psychology, 17(4), 515-535. https://doi.org/10.1023/A:1023404302295.

Carver, C. S., \& Scheier, M. F. (1982). Control theory: A useful conceptual framework for personality-social, clinical, and health psychology. Psychological Bulletin, 92(1), 111-135. https://doi. org/10.1037/0033-2909.92.1.111.

Carver, C. S., \& Scheier, M. F. (2002). Control processes and selforganization as complementary principles underlying behavior. Personality and Social Psychology Review, 6(4), 304-315. https://doi.org/10.1207/S15327957pspr0604_05.

Clark, L. A., \& Watson, D. (1995). Constructing validity: Basic issues in objective scale development. Psychological Assessment, 7(3), 309-319. https://doi.org/10.1037/1040-3590.7.3.309.

DeVellis, R. F. (2003). Scale development: Theory and applications (2nd, Ed. Vol. 26). SAGE Publications.

Edwards, J. R., \& Rothbard, N. P. (2000). Mechanisms linking work and family: Clarifying the relationship between work and family constructs. The Academy of Management Review, 25(1), 178-199. https://doi.org/10.2307/259269.

Ford, M. T., Heinen, B. A., \& Langkamer, K. L. (2007). Work and family satisfaction and conflict: A meta-analysis of cross-domain relations. Journal of Applied Psychology, 92(1), 57-80. https:// doi.org/10.1037/0021-9010.92.1.57.

Fornell, C., \& Larcker, D. F. (1981). Evaluating structural equation models with unobservable variables and measurement error. Journal of Marketing Research, 18(1), 39-50. https://doi.org/10.2307/ 3151312.

Frese, M., \& Zapf, D. (1994). Action as the core of work psychology: A German approach. In H. C. Triandis, M. D. Dunnette, \& L. Hough (Eds.), Handbook of Industrial and Organizational Psychology (Vol. 4, pp. 271-340). Consulting Psychologists Press.

Frese, M., Krauss, S. I., Keith, N., Escher, S., Grabarkiewicz, R., Luneng, S. T., Heers, C., Unger, J., \& Friedrich, C. (2007). Business owners' action planning and its relationship to business success in three African countries. Journal of Applied Psychology, 92(6), 1481-1498. https://doi.org/10.1037/0021-9010.92.6.1481.

Freund, A. M., \& Baltes, P. B. (2002). Life-management strategies of selection, optimization, and compensation: Measurement by selfreport and construct validity. Journal of Personality and Social Psychology, 82, 642-662. https://doi.org/10.1037/0022-3514. 82.4.642.

Geurts, S. A. E., Taris, T. W., Kompier, M. A. J., Dikkers, J. S. E., van Hooff, M. L., \& Kinnunen, U. M. (2005). Work-home interaction from a work psychological perspective: Development and validation of a new questionnaire, the SWING. Work \& Stress, 19(4), 319-339. https://doi.org/10.1080/02678370500410208.

Grant, A. M. (2003). The impact of life coaching on goal attainment, metacognition and mental health. Social Behavior \& Personality: an international journal, 31(3), 253-264. https://doi.org/10.2224/ sbp.2003.31.3.253.

Grawitch, M. J., Barber, L. K., \& Justice, L. (2010). Rethinking the work-life interface: It's not about balance, it's about resource allocation. Applied Psychology: Health and Well-Being, 2(2), 127-159. https://doi.org/10.1111/j.1758-0854.2009.01023.x.

Greenhaus, J. H., \& Beutell, N. J. (1985). Sources of conflict between work and family roles. The Academy of Management Review, 10(1), 76-88. https://doi.org/10.5465/Amr.1985.4277352.

Greenhaus, J. H., \& Kossek, E. E. (2014). The contemporary career: A work-home perspective. Annual Review of Organizational Psychology and Organizational Behavior, 1(1), 361-388. https://doi. org/10.1146/annurev-orgpsych-031413-091324.

Greenhaus, J. H., \& Powell, G. N. (2006). When work and family are allies: A theory of work-family enrichment. Academy of Management Review, 31(1), 72-92. https://doi.org/10.5465/amr.2006. 19379625 .
Groemping, U. (2006). Relative Importance for Linear Regression in R: The Package relaimpo. 17(1), 27. https://doi.org/10.18637/jss. v017.i01.

Hinkin, T. R., Tracey, J. B., \& Enz, C. A. (1997). Scale construction: Developing reliable and valid measurement instruments. Journal of Hospitality \& Tourism Research, 21(1), 100-120. https://doi. org/10.1177/109634809702100108.

Hirschi, A., Shockley, K. M., \& Zacher, H. (2019). Achieving workfamily balance: An action regulation model. Academy of Management Review, 44(1), 150-171. https://doi.org/10.5465/amr.2016. 0409 .

Hobfoll, S. E., Halbesleben, J., Neveu, J.-P., \& Westman, M. (2018). Conservation of resources in the organizational context: The reality of resources and their consequences. Annual Review of Organizational Psychology and Organizational Behavior, 5(1), 103-128. https://doi.org/10.1146/annurev-orgpsych-032117-104640.

Hofstede, G. (2001). Culture's consequences : comparing values, behaviors, institutions, and organizations across nations. Sage Publications.

Holden, R. R., \& Jackson, D. N. (1979). Item subtlety and face validity in personality assessment. Journal of Consulting and Clinical Psychology, 47, 459-468. https://doi.org/10.1037/0022-006X. 47.3.459.

Karoly, P. (1993). Mechanisms of self-regulation - A systems view. Annual Review of Psychology, 44, 23-52. https://doi.org/10.1146/ annurev.ps.44.020193.000323.

Klein, H. J. (1989). An integrated control-theory model of work motivation. Academy of Management Review, 14(2), 150-172. https:// doi.org/10.2307/258414.

Kossek, E. E., Ruderman, M. N., Braddy, P. W., \& Hannum, K. M. (2012). Work-nonwork boundary management profiles: A person-centered approach. Journal of Vocational Behavior, 81(1), 112-128. https://doi.org/10.1016/j.jvb.2012.04.003.

Lapierre, L. M., Li, Y., Kwan, H. K., Greenhaus, J. H., DiRenzo, M. S., \& Shao, P. (2018). A meta-analysis of the antecedents of workfamily enrichment. Journal of Organizational Behavior, 39(4), 385-401. https://doi.org/10.1002/job.2234.

Lee, C., Bobko, P., Earley, P. C., \& Locke, E. A. (1991). An empirical analysis of a goal setting questionnaire. Journal of Organizational Behavior, 12(6), 467-482. https://doi.org/10.1002/job. 4030120602.

Locke, E. A., \& Latham, G. P. (1990). A theory of goal setting and task performance. Prentice Hall.

Lord, R. G., Diefendorff, J. M., Schmidt, A. M., \& Hall, R. J. (2010). Self-regulation at work. Annual Review of Psychology, 61, 543568. https://doi.org/10.1146/annurev.psych.093008.100314.

Luszczynska, A., Diehl, M., Gutiérrez-Doña, B., Kuusinen, P., \& Schwarzer, R. (2004). Measuring one component of dispositional self-regulation: Attention control in goal pursuit. Personality and Individual Differences, 37(3), 555-566. https://doi.org/10.1016/j. paid.2003.09.026.

Macan, T. H., Shahani, C., Dipboye, R. L., \& Phillips, A. P. (1990). College students' time management: correlations with academic performance and stress. Journal of Educational Psychology, 82(4), 760-768. https://doi.org/10.1037/0022-0663.82.4.760.

Marks, S. R., \& MacDermid, S. M. (1996). Multiple roles and the self: A theory of role balance. Journal of Marriage and Family, 58(2), 417-432. https://doi.org/10.2307/353506.

Meade, A. W., \& Craig, S. B. (2012). Identifying careless responses in survey data. Psychological Methods, 17(3), 437-455. https://doi. org/10.1037/a0028085.

Michel, J. S., Kotrba, L. M., Mitchelson, J. K., Clark, M. A., \& Baltes, B. B. (2011). Antecedents of work-family conflict: A meta-analytic review. Journal of Organizational Behavior, 32(5), 689-725. https://doi.org/10.1002/job.695. 
Moghimi, D., Zacher, H., Scheibe, S., \& Van Yperen, N. W. (2017). The selection, optimization, and compensation model in the work context: A systematic review and meta-analysis of two decades of research. Journal of Organizational Behavior, 38(2), 247-275. https://doi.org/10.1002/job.2108.

Nitzsche, A., Jung, J., Pfaff, H., \& Driller, E. (2013). Employees' negative and positive work-home interaction and their association with depressive symptoms. American Journal of Industrial Medicine, 56(5), 590-598. https://doi.org/10.1002/ajim.22121.

OECD. (2017). OECD Family database: PF2.1 Key characteristics of parental leave systems. http://www.oecd.org/els/family/datab ase.htm.

Reilly, M. D. (1982). Working wives and convenience consumption. Journal of Consumer Research, 8(4), 407-418. https://doi.org/ $10.1086 / 208881$

Seiger, C. P., \& Wiese, B. S. (2009). Social support from work and family domains as an antecedent of moderator in work-family conflicts? Journal of Vocational Behavior, 75, 26-37. https://doi. org/10.1016/j.jvb.2009.03.001.

Shockley, K. M. (2018). Managing the work-family interface. In C. V. N. Anderson, H.K. Sinangil \& D. Ones (Ed.), Handbook of Industrial, Work, and Organizational Psychology (pp. 604-627). Sage.

Shockley, K. M., Shen, W., DeNunzio, M. M., Arvan, M. L., \& Knudsen, E. A. (2017). Disentangling the relationship between gender and work-family conflict: An integration of theoretical perspectives using meta-analytic methods. Journal of Applied Psychology, 102(12), 1601-1635. https://doi.org/10.1037/ap10000246.

Sitzmann, T., \& Ely, K. (2011). A meta-analysis of self-regulated learning in work-related training and educational attainment: What we know and where we need to go. Psychological Bulletin, 137(3), 421-442. https://doi.org/10.1037/a0022777.

ten Brummelhuis, L. L., \& Bakker, A. B. (2012). A resource perspective on the work-home interface: The work-home resources model. American Psychologist, 67(7), 545-556. https://doi.org/ 10.1037/a0027974.

Thiagarajan, P., Chakrabarty, S., \& Taylor, R. D. (2006). A confirmatory factor analysis of Reilly's role overload scale. Educational and Psychological Measurement, 66(4), 657-666. https://doi.org/ 10.1177/0013164405282452.

Tonidandel, S., \& LeBreton, J. M. (2011). Relative importance analysis: A useful supplement to regression analysis. Journal of Business and Psychology, 26(1), 1-9. https://doi.org/10.1007/ s10869-010-9204-3.

Unsworth, K., Yeo, G., \& Beck, J. (2014). Multiple goals: A review and derivation of general principles. Journal of Organizational Behavior, 35(8), 1064-1078. https://doi.org/10.1002/job.1963.

Voydanoff, P. (2005). Toward a conceptualization of perceived workfamily fit and balance: A demands and resources approach. Journal of Marriage and Family, 67(4), 822-836. https://doi.org/10. 1111/j.1741-3737.2005.00178.x.

Wepfer, A. G., Allen, T. D., Brauchli, R., Jenny, G. J., \& Bauer, G. F. (2018). Work-life boundaries and well-being. Journal of Business and Psychology, 33(6), 727-740. https://doi.org/10.1007/ s10869-017-9520-y.

Zacher, H., \& Frese, M. (2018). Action regulation theory: Foundations, current knowledge, and future directions. In N. Anderson, D. S. Ones, C. Viswesvaran, \& H. K. Sinangil (Eds.), The SAGE Handbook of Industrial, Work, \& Organizational Psychology (2nd ed., Vol. 2, pp. 80-102). Sage.

Zacher, H., Hacker, W., \& Frese, M. (2016). Action regulation across the adult lifespan (ARAL): A metatheory of work and aging. Work, Aging and Retirement, 2(3), 286-306. https://doi.org/10. 1093/workar/waw015.

Zimet, G. D., Dahlem, N. W., Zimet, S. G., \& Farley, G. K. (1988). The multidimensional scale of perceived social support. Journal of Personality Assessment, 52(1), 30-41. https://doi.org/10.1207s 15327752jpa5201_2.

Publisher's Note Springer Nature remains neutral with regard to jurisdictional claims in published maps and institutional affiliations. 